\title{
Prediksi Peserta Matakuliah Menggunakan Artificial Neural Network - Fuzzy Inferented System (Ann-Fis) Studi Kasus: Universitas Muhammadiyah Surakarta
}

\author{
Noto Narwanto ${ }^{1} \quad$ Kusrini $^{2} \quad$ Hanif Al Fatta $^{3}$ \\ Program Studi Teknik Informatika AMIKOM Yogyakarta \\ Email: ${ }^{1}$ nnarwanto@gmail.com , ${ }^{2}$ kusrini@amikom.ac.id , ${ }^{3}$ hanif.a@amikom.ac.id
}

\begin{abstract}
Abstrak: Pengelolaan sebuah institusi perguruan yang efektif dan efisien sangat diperlukan, yaitu dengan memanfaatkan sumber daya semaksimal mungkin. Salah satu kendala dalam pengelolaan adalah tidak meratanya jumlah peserta kuliah yang disebabkan oleh jumlah kelas yang disediakan lebih banyak dari kebutuhan seharusnya. Semisal satu matakuliah cukup dengan 2 kelas tapi dibuka 4 kelas. Hal ini terjadi karena prodi belum mampu memperkirakan berapa kira-kira peserta yang akan mengambil matakuliah tersebut. Penelitian ini bertujuan membantu untuk memperkirakan berapa jumlah mahasiswa yang mengambil suatu matakuliah dengan menggunakan data-data lama sebagai pertimbangannya. Metode ANFIS (Adaptif Neural Fuzzy Inferented System) yaitu gabungan Jaringan Syaraf Tiruan dan Fuzzy. Jaringan syaraf tiruan digunakan untuk sistem pembelajarnya dan fuzzy digunakan untuk perkiraan jumlah pesertanya, dengan menggunakan beberapa variabel yang sudah disortir dengan sistem regresi, seperti mahasiswa yang seharusnya mengambil, jumlah mahasiswa yang belum lulus dan juga mahasiswa yang berpotensi mengulang (nilainya $\mathrm{C}, \mathrm{CB}$ ). Variabel tersebut untuk selanjutnya diolah menggunakan ANFIS. Variabel-variabel terpilih diuji dengan metode ANFIS yang menghasilkan error 16,3. Hal ini berarti rata-rata hasil perhitungan tool dan data asli memiliki selisih 16.3. Angka ini diklasifikasikan sebagai nilai yang cukup besar untuk peluang membuka kelas baru.
\end{abstract}

Kata Kunci: ANFIS, Fuzzy, JST

\begin{abstract}
An effective and efficient management of a university institution is needed, namely by utilizing the resources as much as possible. One obstacle in management is the unequal number of lecture participants caused by the number of classes being provided that are more than they need to be. Such as one course enough with 2 classes but opened 4 classes. This happens because the study program has not been able to estimate how many participants will take the course.

This study aims to help estimate how many students take a course by using old data as consideration. The ANFIS (Adaptive Neural Fuzzy Inferented System) method is a combination of Artificial Neural Networks and Fuzzy. Artificial neural networks are used for the learning system and fuzzy is used to estimate the number of participants, using several variables that have been sorted by a regression system, such as students who should take, the number of students who have not graduated and also students who have the potential to repeat (values $C, C B$ ). These variables are then processed using ANFIS.

The selected variables were tested with ANFIS which produced an error of 16.3. This means that the average results of calculation tools and original data have a difference of 16.3. This number is classified as a large enough value for opportunities to open new classes.
\end{abstract}

Keywords: ANFIS, Fuzzy, JST 


\section{PENDAHULUAN}

Universitas Muhammadiyah Surakarta merupakan salah satu perguruan tinggi di Jawa Tengah dengan jumlah mahasiswa aktif lebih dari tiga puluh ribu (30.000) tiap semesternya. Proses belajar mengajar sangat membutuhkan ruang, pengampu, jadwal kuliah dan sarana pembelajaran lainnya. Kebutuhan ruang dan pengampu sangat tergantung pada berapa jumlah mahasiswa yang terdaftar pada suatu matakuliah. Pemanfaatan ruang yang optimal dapat menghemat alokasi anggaran tanpa harus menyediakan ruang baru.

Peneliti mencoba merancang model untuk memprediksi jumlah peserta matakuliah dengan berdasarkan pada data historis semestersemester sebelumnya. Hasil prediksi ini diharapkan mampu dijadikan pertimbangan untuk menentukan berapa kelas yang harus disediakan dan menyusun jadwal lebih awal untuk satu matakuliah, sehingga kebutuhan kelas dapat terpenuhi dengan baik dan mahasiswa dapat memilih jadwal sesuai keinginan lebih cepat.

Penelitian menggunakan NN pernah dilakukan, yang meneliti mengenai lama masa studi mahasiswa menggunakan jaringan syaraf tiruan (ANN), penelitian ini memprediksi lama masa studi berdasarkan index prestasi[1]

Metode yang peneliti gunakan adalah kombinasi dari Artificial Neural Network dan Fuzzy System (ANFIS). Karakteristik ANFIS sangat berguna terutama untuk sistem pemodelan yang tidak memiliki deskripsi analitis, tetapi perilaku dapat dijelaskan oleh pakar[2]. Hasil peramalan dengan metode ANFIS menunjukkan bahwa error yang dihasilkan relatif kecil, pada kasus penggunaan air[3]. Variabel yang dianggap berpengaruh dipilih dua yang bobot/kontribusi tertinggi. Pemilihan bobot variabel dominan menggunakan metode regresi yaitu memasukkan semua variabel dan memilih dua variabel yang memiliki bobot/pengaruh signifikan terhadap output tertinggi.

Regresi berganda adalah model regresi atau prediksi yang melibatkan lebih dari satu variabel bebas atau prediktor [4]. Istilah regresi berganda dapat disebut juga dengan istilah multiple regression. Kata multiple berarti jamak atau lebih dari satu variabel.

Jaringan Syaraf Tiruan(JST/NN=neural network) adalah paradigma pemrosesan suatu informasi yang terinspirasi oleh sistim sel syaraf biologi, sama seperti otak yang memproses suatu informasi. Elemen mendasar dari paradigma tersebut adalah struktur yang baru dari sistim pemrosesan informasi. JST, seperti manusia, belajar dari suatu contoh. JST dibentuk untuk memecahkan suatu masalah tertentu seperti pengenalan pola atau klasifikasi karena proses pembelajaran. Pemakaian metode neural network (NN) sudah banyak dilakukan terutama dalam hal prediksi hasil yang tidak pasti. Metode NN memiliki akurasi maksimum dan kesalahan minimum [5].

Logika fuzzy memiliki derajat keanggotaan rentang antara 0 hingga 1 , berbeda dengan logika digital yang hanya memiliki dua keanggotaan 0 atau 1 saja pada satu waktu. Logika fuzzy sering digunakan untuk mengekspresikan suatu nilai yang diterjemahkan dalam bahasa (linguistic), semisal untuk mengekspresikan suhu dalam ruangan apakah ruangan tersebut dingin, hangat, atau panas. Logika Fuzzy berpotensi memecahkan masalah ketidakpastian[6].

ANFIS pada dasarnya adalah representasi jaringan sistem fuzzy type Sugeno yang memiliki kemampuan belajar. Jaringan ini terdiri dari node dengan fungsi spesifik yang dikumpulkan dalam lapisan

\section{METODE PENELITIAN}

\section{A. Pengumpulan data}

Pengumpulan data dilakukan dengan memakai data arsip yang tersimpan di database antara semester 20161 sampai dengan tahun 20182. Penelitian ini fokus pada program studi Pendidikan Matematika pada matakuliah wajib.

\section{B. Uji Variabel Dominan}

Tahapan ini akan dilakukan uji variabel dominan yaitu mencarai besaran kontribusi variabel-variabel input dalam menentukan output. Metode yang digunakan adalah regresi, dari variabel-variabel yang diuji dipilih dua variabel yang berpengaruh atau yang memiliki kontribusi paling besar.

Penggunaan regresi banyak dilakukan para peneliti salah satunya adalah Ali Imran mukti, dkk [7]. Analisis regresi linier berganda (MLRA) telah dilakukan yang melibatkan variabel dependen DO, dan tiga variabel independen, yaitu T, TSS, dan kedalaman (Dh). Hasil penelitian tersebut menyatakan bahwa analisis dan model regresi linier berganda dapat digunakan untuk mengekspresikan suatu perubahan hubungan fungsional dalam konsentrasi oksigen terlarut- 
DO terhadap perubahan parameter fisiko-kimia dari T, TSS, dan Dh, sungai Secang.

\section{Pengujian}

Variabel yang terpilih kemudian dijadikan variabel input pada metode ANFIS baik dari sisi pembelajaran maupun data uji. Hal ini bertujuan untuk mendapatkan kesimpulan apakah metode dan variabel yang dipilih sesuai dan layak digunakan untuk memprediksi jumlah peserta matakuliah.

\section{RMSE (Root Mean Square Error)}

RMSE adalah metode alternatif untuk mengevaluasi teknik peramalan yang digunakan untuk mengukur tingkat akurasi hasil prakiraan suatu model. RMSE merupakan nilai rata-rata dari jumlah kuadrat kesalahan, juga dapat menyatakan ukuran besarnya kesalahan yang dihasilkan oleh suatu model prakiraan. Nilai RMSE rendah menunjukkan bahwa variasi nilai yang dihasilkan oleh suatu model prakiraan mendekati variasi nilai obeservasinya.

\section{HASIL DAN PEMBAHASAN}

\section{A. Pengumpulan data}

Tabel 1. Data peserta matakuliah

\begin{tabular}{|c|c|c|c|c|c|c|c|}
\hline SMT & $\begin{array}{l}\text { SMT } \\
\text { MK }\end{array}$ & $\mathrm{X}_{1}$ & $\mathrm{X}_{2}$ & $\mathrm{X}_{3}$ & $\mathrm{X}_{4}$ & $\mathrm{X}_{5}$ & $\mathrm{Y}$ \\
\hline 20161 & 3 & 220 & 1.77 & 2.91 & 28 & 119 & 346 \\
\hline 20161 & 3 & 220 & 2.47 & 2.91 & 66 & 88 & 223 \\
\hline 20161 & 5 & 268 & 2.23 & 2.91 & 53 & 60 & 309 \\
\hline 20161 & 5 & 268 & 3.23 & 2.91 & 20 & 22 & 138 \\
\hline 20162 & 4 & 220 & 3.61 & 3.07 & 1 & 2 & 219 \\
\hline 20162 & 4 & 220 & 3.26 & 3.07 & 5 & 4 & 208 \\
\hline 20162 & 4 & 220 & 3.91 & 3.07 & 0 & 0 & 209 \\
\hline 20171 & 5 & 220 & 2.36 & 3.13 & 47 & 96 & 285 \\
\hline 20171 & 5 & 220 & 3.41 & 3.13 & 12 & 0 & 195 \\
\hline 20171 & 5 & 220 & 3.68 & 3.13 & 1 & 4 & 225 \\
\hline 20172 & 4 & 251 & 3.62 & 3.13 & 3 & 0 & 235 \\
\hline 20172 & 4 & 251 & 3.68 & 3.13 & 1 & 0 & 237 \\
\hline 20172 & 4 & 251 & 3.94 & 3.13 & 0 & 0 & 237 \\
\hline 20172 & 4 & 251 & 2.78 & 3.13 & 47 & 57 & 251 \\
\hline 20172 & 4 & 251 & 3.34 & 3.13 & 18 & 1 & 243 \\
\hline 20172 & 4 & 251 & 3.03 & 3.13 & 39 & 5 & 251 \\
\hline 20172 & 4 & 251 & 3.32 & 3.13 & 22 & 26 & 243 \\
\hline 20172 & 4 & 251 & 3.64 & 3.13 & 5 & 0 & 240 \\
\hline 20181 & 5 & 251 & 3.5 & 3.26 & 4 & 2 & 224 \\
\hline 20181 & 5 & 251 & 2.21 & 3.26 & 58 & 87 & 314 \\
\hline 20181 & 5 & 251 & 3.15 & 3.26 & 33 & 22 & 239 \\
\hline 20181 & 5 & 251 & 3.04 & 3.26 & 31 & 0 & 174 \\
\hline 20182 & 4 & 135 & 3.52 & 3.01 & 17 & 1 & 123 \\
\hline 20182 & 4 & 135 & 3.8 & 3.01 & 4 & 0 & 129 \\
\hline 20182 & 4 & 135 & 3.95 & 3.01 & 0 & 0 & 128 \\
\hline 20182 & 4 & 135 & 3.62 & 3.01 & 4 & 0 & 118 \\
\hline
\end{tabular}

Peneliti menggunakan data dari semester 20161 sampai dengan 20182 didapatkan data seperti pada tabel 1 .

$\mathrm{Y}=$ Jumlah peserta matakuliah.
$\mathrm{X}_{1}=$ Jumlah mahasiswa baru yang seharusnya mengambil matakuliah yang sesuai semesternya.
$\mathrm{X}_{2}=$ IP matakuliah tahun semester sebelumnya
$\mathrm{X}_{3}=$ IP Mahasiswa Semester sebelumnya
$\mathrm{X}_{4}=$ Nilai BC $(2,5)$ pada tahun semester sebelumnya
$\mathrm{X}_{5}=$ Nilai $\mathrm{C}$ (2) pada tahun semester sebelumnya

Penjelasan semester pengambilan data: Jika Y adalah semester 20171, maka:

$$
\begin{aligned}
& \mathrm{Y}_{1}=\begin{array}{l}
\text { Jumlah peserta matakuliah. } \\
\mathrm{X}_{1}= \\
\text { untuk matakuliah semester 1 maka } \\
\text { mahasiswa angkatan 2017, } \\
\text { matakuliah semester 3 maka } \\
\text { mahasiswa angkatan 2016, dan } \\
\text { seterusnya. }
\end{array} \\
& \mathrm{X}_{2}=\begin{array}{l}
\text { IP matakuliah yang sama pada tahun } \\
\text { sebelumnya yaitu 20161 }
\end{array} \\
& \mathrm{X}_{3}=\begin{array}{l}
\text { IP Mahasiswa semester sebelumnya } \\
\text { yaitu 20162 }
\end{array} \\
& \mathrm{X}_{4}=\begin{array}{l}
\text { Nilai BC }(2,5) \text { pada tahun semester } \\
\text { sebelumnya yaitu 20161 }
\end{array} \\
& \mathrm{X}_{5}=\begin{array}{l}
\text { Nilai } \mathrm{C}(2) \text { pada tahun semester } \\
\text { sebelumnya yaitu 20161 }
\end{array}
\end{aligned}
$$

\begin{tabular}{|c|c|c|c|c|c|c|}
\hline & Coeff & $\begin{array}{c}\text { Std } \\
\text { Error }\end{array}$ & $t$ Stat & $P$-value & $\begin{array}{c}\text { Lower } \\
95 \%\end{array}$ & $\begin{array}{c}\text { Upper } \\
95 \%\end{array}$ \\
\hline Intercept & 89.69 & 102.21 & 0.87 & 0.38 & -114.43 & 293.82 \\
\hline $\mathrm{X}_{1}$ & 0.85 & 0.09 & 9.42 & $8.83 \mathrm{E}-14$ & 0.67 & 1.03 \\
\hline $\mathrm{X}_{2}$ & -19.96 & 12.89 & -1.54 & 0.12 & -45.71 & 5.78 \\
\hline$X_{3}$ & 2.41 & 29.52 & 0.08 & 0.93 & -56.54 & 61.37 \\
\hline $\mathrm{X}_{4}$ & -0.61 & 0.23 & -2.56 & 0.01 & -1.09 & -0.13 \\
\hline $\mathrm{X}_{5}$ & 0.59 & 0.20 & 2.88 & 0.00 & 0.181 & 0.99 \\
\hline
\end{tabular}

\section{B. Uji Variabel Dominan}

Pengujian variabel dominan menggunakan tool didapatkan hasil seperti pada tabel 2 .

Tabel 2. Koefisien

Berdasarkan tabel 2. Didapatkan hasil bahwa koefisian tertinggi 3 variabel berurutan adalah, $\mathrm{X}_{3}=2.41 \quad, \quad \mathrm{X}_{1}=0.85$ dan $\mathrm{X}_{5}=0.59$. variabel berpengaruh diurutkan dari yang memiliki koefisien tertinggi dengan catatan $\mathrm{p}$-value tidak melebihi batas toleransi yaitu $5 \%(0.05) . \mathrm{x}_{1}, \mathrm{x}_{3}$ dan $\mathrm{x}_{5}$ memiliki $\mathrm{p}$-value berurutan sebesar:8.8 $\times 10^{-14}$, 0.93 dan $5.3 \times 10^{-3}$. Maka variabel yang memenuhi syarat adalah $\mathrm{x}_{1}$ dan $\mathrm{x}_{5}$. 


\section{Pengujian ANFIS}

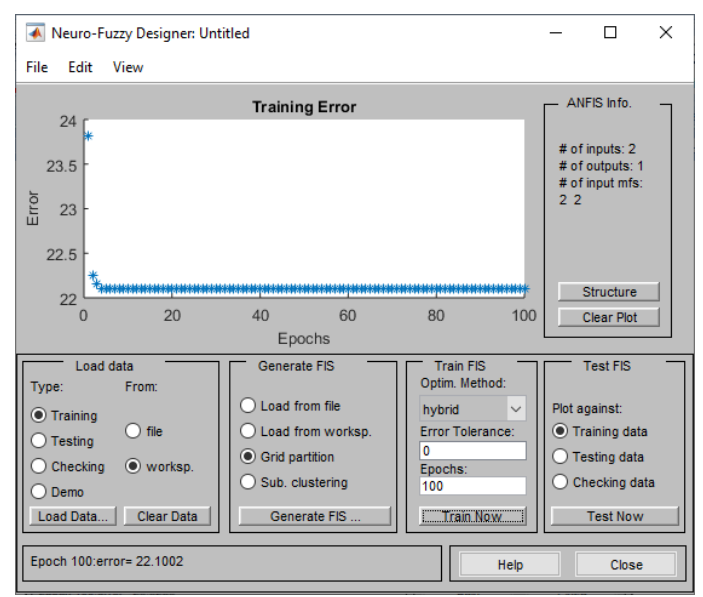

Gambar 1.Trainning ANFIS

Gambar 1. menunjukkan hasil training yang dilakukan dengan epoch sebanyak 100, input 2 variabel $\left(\mathrm{x}_{1}\right.$ dan $\left.\mathrm{x}_{5}\right)$ dan rules $2 \times 2$. Terlihat dari grafik menunjukkan rata-rata error sebesar 22.1.

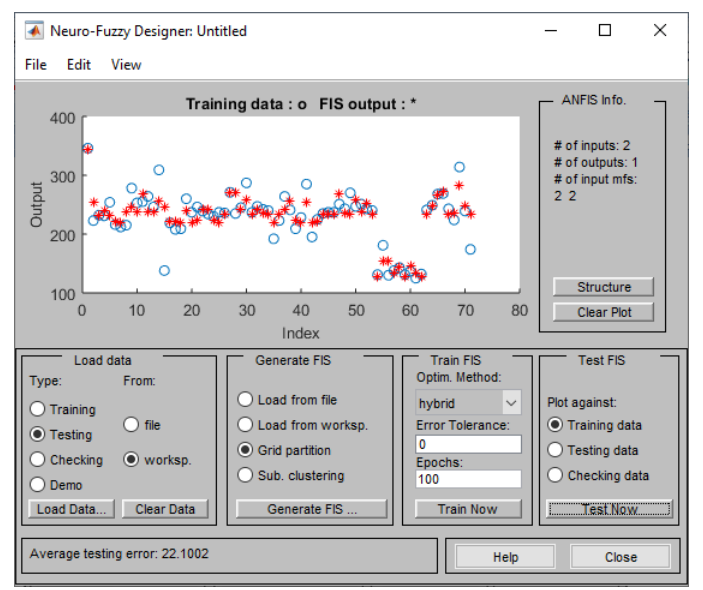

Gambar 2.Grafik data training dan data uji

Gambar 2. memperlihatkan hubungan antara hasil data trainning (bulat warna biru) dengan data hasil testing (bintang warna merah) dengan menggunakan data yang sama. Data yang dipakai untuk trainning digunakan kembali untuk data testing.

Sebagian pola menunjukkan posisi berhimpitan/dekat sebagian agak jauh. Pola gambar berhimpitan dapat diartikan antara trainning dan uji mendekati sama, sebaliknya apabila berjauhan dapat disimpulkan bahwa trainning dan uji mengalami perbedaan hasil yang signifikan. Rata-rata error testing adalah 22.01.

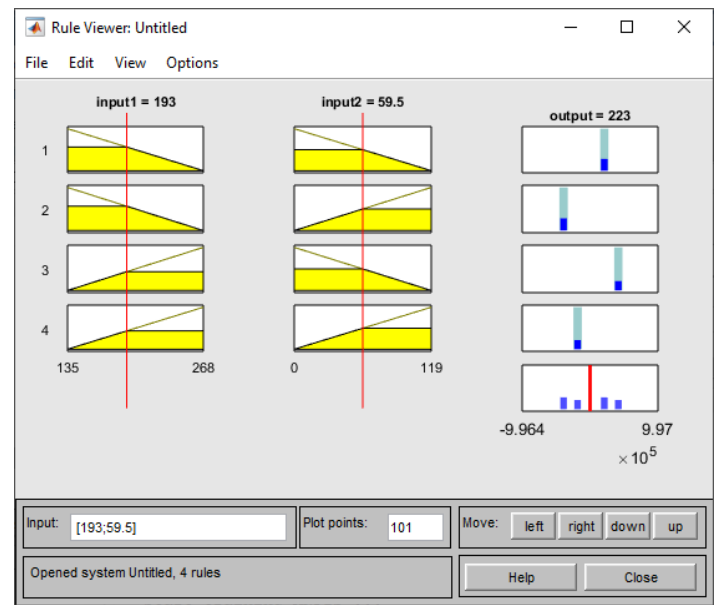

Gambar 3. Grafik rule yang terbentuk

Gambar 3 memperlihatkan rule/aturan yang terbentuk, terlihat grafik untuk input 1 dan input 2 serta output. Sebagai contoh apabila $\mathrm{x}_{1}=135$ dan $\mathrm{x}_{5}=17$ maka $_{\bar{y}}=145$, dengan pola yang sama kita ujikan semua data yang ada pada semester 20182 didapatkan hasil seperti pada tabel 3 .

Tabel 3.hasil uji ANFIS

\begin{tabular}{|c|c|c|c|c|c|r|}
\hline SEM & $\begin{array}{c}\text { SEM } \\
\text { MK }\end{array}$ & $\mathrm{X} 1$ & $\mathrm{X} 5$ & $\mathrm{y}$ & $\bar{y}$ & Selisin \\
\hline 20182 & 4 & 135 & 17 & 123 & 145 & 22 \\
\hline 20182 & 4 & 135 & 4 & 129 & 141 & 12 \\
\hline 20182 & 4 & 135 & 0 & 128 & 140 & 12 \\
\hline 20182 & 4 & 135 & 40 & 135 & 153 & 18 \\
\hline 20182 & 4 & 135 & 0 & 131 & 140 & 9 \\
\hline 20182 & 4 & 135 & 5 & 130 & 141 & 11 \\
\hline 20182 & 4 & 135 & 57 & 131 & 158 & 27 \\
\hline 20182 & 4 & 135 & 22 & 129 & 147 & 18 \\
\hline 20182 & 4 & 135 & 4 & 130 & 141 & 11 \\
\hline 20182 & 4 & 135 & 4 & 118 & 141 & 23 \\
\hline
\end{tabular}

Dari tabel 3 didapatkan hasil bahwa selisih output antara y asli dan ȳ uji rata-rata 16.3 sedangkan toleransi yang ditargetkan sebesar 10 .

\section{RMSE}

Dengan mengacu pada tabel 3 didapatkan hasil RMSE sebagai berikut:

$$
\begin{aligned}
\text { RMSE } & =\sqrt{\frac{\sum_{i=0}^{i=n}(y i-\bar{y} i)}{n}} \\
& =\sqrt{\frac{3001}{10}} \\
& =17.32
\end{aligned}
$$

$\mathrm{y}=$ nilai hasil observasi

$\overline{\mathrm{y}}=$ nilai hasil prediksi

$\mathrm{i}=$ urutan data pada database

$\mathrm{n}=$ jumlah data

Dari perhitungan diatas didapatkan RMSE sebesar 17.32 hal ini sangat jauh dari 
angka ideal 0 . Toleransi kesalahan hitung penelitian ini menetapkan 10 , selisih antara data asli dengan data uji diperkirakan sekitar 10 (mahasiswa).

\section{KESIMPULAN}

Berdasarkan pembahasan diatas maka dapat disimpulkan bahwa:

a) Varabel yang berpengaruh terhadap peserta kuliah berurutan dari kontribusi terbesar adalah Jumlah mahasiswa baru $\left(\mathrm{X}_{1}\right)$, mahasiswa mengulang dengan nilai sebelumnya $\mathrm{C}\left(\mathrm{X}_{5}\right)$

b) Apabila diambil dua variable dan dilakukan ujicoba menggunakan metode ANFIS didapatkan hasil rata selisih 16,3 hal ini menunjukkan dengan variabel, cara dan metode seperti diatas hasil prediksi cenderung lebih besar dibanding dengan data aslinya. Seperti ditunjukkan pada tabel 3.

c) Nilai RMSE sebesar 17.32 menunjukkan akurasi data masih rendah jarena jauh dari angka 0 .

\section{DAFTAR PUSTAKA}

[1] Rahmani, B, 2013, Pengembangan Model Prediksi Lama Masa Studi Mahasiswa Berbasis Jaringan Syaraf Tiruan, Prosiding seminar nasional 2013, menujumasyarakat madani dan lestari, ISBN: 978-979-984388-3.

[2] Walia.N, Singh.H and Sharma.A, 2015, ANFIS: Adaptive Neuro-Fuzzy Inference System- A Survey, International Journal of Computer Applications (0975 - 8887) Volume 123 - No.13, August 2015

[3] Hani'ah.U, Arifudin.R dan Sugiharti.E, 2016, Implementasi Adaptive Neuro-Fuzzy Inference System (Anfis) untuk Peramalan Pemakaian Air di Perusahaan Daerah Air Minum Tirta Moedal Semarang, Scientific Journal of Informatics Vol. 3, No. 1, Mei 2016 p-ISSN 2407-7658 e-ISSN 24600040.

[4] Penjelasan Berbagai Jenis Regresi Berganda.[Online], https://www.statistikian.com/2017/06/berb agai-jenis-regresi-berganda.html, tanggal akses: 25 Desember 2019.

[5] Sayadi dkk, 2013, A comparative study on the application of various artificialneural networks to simultaneous prediction of rock fragmentation and backbreak, Journal of
Rock Mechanics and Geotechnical Engineering 5 (2013) 318-324.

[6] Fuad, M, 2011, Prediksi Ketersediaan Beras di Masyarakat Dengan Menggunakan Logika Fuzzy dan Jaringan Syaraf Tiruan Dalam Upaya Peningkatan Ketahanan Pangan, Agrointex Vol 5 No 1 MAret 2011, Univ Trunojoyo Madura.

[7] Mukti AI, Sugiharto E, Dwi S, 2014, Penggunaan Model Regresi Linier untuk Menyatakan Hubungan Fungsional Perubahan Konsentrasi Oksigen Terlarut terhadap Parameter Fisika-kimia Air Sungai Secang Kulon Progo, Berkala MIPA UGM 2014. 